\title{
Relative Tendency of Carbonyl Compounds To Form Enamines
}

\author{
Dani Sánchez, David Bastida, Jordi Burés, Carles Isart, Oriol Pineda, and \\ Jaume Vilarrasa*
}

Departament de Química Orgànica, Facultat de Química, Universitat de Barcelona, Diagonal 645, 08028 Barcelona, Catalonia, Spain

jvilarrasa@ub.edu

Received November 25, 2011

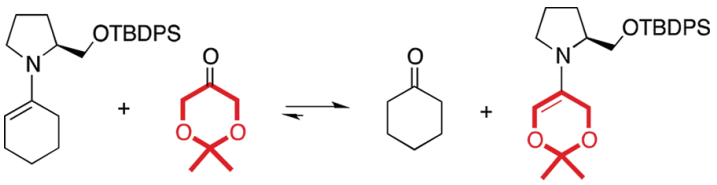

Equilibria between carbonyl compounds and their enamines (from 0-TBDPS-derived prolinol) have been examined by NMR spectroscopy in DMSO- $d_{6}$. By comparing the exchange reactions between pairs (enamine A + carbonyl B $\rightarrow$ carbonyl A + enamine B), a quite general scale of the tendency of carbonyl groups to form enamines has been established. Aldehydes quickly give enamines that are relatively more stable than those of ketones, but there are exceptions to this expected rule; for example, 1,3-dihydroxyacetone acetals or 3,5-dioxacyclohexanones (2-phenyl-1, 3-dioxan-5-one and 2,2-dimethyl-1,3-dioxan-5-one) show a greater tendency to afford enamines than many $\alpha$-substituted aldehydes.

The renaissance of enamine chemistry ${ }^{1}$ over the past 10 years, as secondary amine-catalyzed direct reactions of carbonyl compounds with electrophiles (enamine catalysis), has already given rise to around 1300 reports and 110 reviews. ${ }^{2}$ Due to our interest in Michael reactions, ${ }^{3}$ including organocatalytic reactions involving nitroalkenes, ${ }^{3 \mathrm{c}-\mathrm{f}}$ and in the conversion of the nitro groups into carbonyl compounds by procedures mild enough to be applicable to

(1) For historical reviews, see: (a) Hickmott, P. W. Tetrahedron 1982 , 38, 1975-2050. (b) Stork, G. Med. Res. Rev. 1999, 19, 370-387. (c) Stork, G. Tetrahedron 2011, 67, 9754-9764. Also see:(d) Seebach, D.; Beck, A. K.; Badine, D. M.; Limbach, M.; Eschenmoser, A.; Treasurywala, A. M.; Hobi, R.; Prikoszovich, W.; Linder, B. Helv. Chim. Acta 2007, 90, 425-471.

(2) For very recent, representative reviews, see: (a) Jensen, K. L.; Dickmeiss, G.; Jiang, H.; Albrecht, L.; Jørgensen, K. A. Acc. Chem. Res. 2011, DOI: 10.1021/ar200149w. (b) Nielsen, M.; Worgull, D.; Zweifel, T.; Gschwend, B.; Bertelsen, S.; Jørgensen, K. A. Chem. Commun. 2011, 47, 632-649. (c) Trost, B. M.; Brindle, C. S. Chem. Soc. Rev, 2010, 39, 16001632. (d) Roca-Lopez, D.; Sadaba, D.; Delso, I.; Herrera, R. P.; Tejero, T.; Merino, P. Tetrahedron: Asymmetry 2010, 21, 2561-2601. (e) Xu, L.-W.; Li, L.; Shi, X.-H. Adv. Synth. Catal. 2010, 352, 243-279. Also see: (f) Wiesner, M.; Upert, G.; Angelici, G.; Wennemers, H. J. Am. Chem. Soc. 2010, 132, 6-7 and refs 2 and 3 therein

(3) (a) Olivella, A.; Rodríguez-Escrich, C.; Urpí, F.; Vilarrasa, J. J. Org. Chem. 2008, 73, 1578-1581. (b) Esteban, J.; Costa, A. M.; Gómez, A.; Vilarrasa, J. Org. Lett. 2008, 10, 65-68. (c) RodríguezEscrich, C. Master Thesis, Universitat de Barcelona (UB), 2003 (d) Isart, C. Master Thesis, UB, 2005. (e) Sánchez, D. Master Thesis, UB, 2009. (f) Carneros, H. Master Thesis, UB, 2011. (g) Llàcer, E. Ph.D. Thesis (Total Synthesis of Fluvirucins), UB, 2012 complex polyfunctional fragments, ${ }^{4}$ we focused on very recent, outstanding studies by Seebach et al., ${ }^{5 a}$ Gschwind et al., ${ }^{5 \mathrm{~b}}$ and List et al. ${ }^{5 \mathrm{c}}$ in which special examples of stable enamines were characterized. ${ }^{5}$ These papers prompted us to report the results that we obtained with $O$-tertbutyldiphenylsilyl-( $S$ )-prolinol, 1, the catalytic performance of which was first examined by Peng et al. ${ }^{6}$ We chose this catalyst because the bulky substituent (TBDPS group) is away from the $\alpha$ position of the pyrrolidine ring, which permits the attack of its amine not only on aldehydes but also on much less reactive ketones (with which catalysts such as those of MacMillan and Jørgensen-Hayashi, more hindered sterically, do not form detectable amounts of enamines). In this context, we disclose here which enolizable carbonyl compounds show a higher tendency to form enamines with pyrrolidine derivative 1 (Scheme 1).

When standard enolizable aldehydes, such as benzeneacetaldehye (phenylethanal), isovaleraldehyde (3-methylbutanal), cyclohexanecarboxaldehyde, or isobutyraldehyde (2-methylpropanal), were mixed with equimolar amounts of 1 in anhydrous DMSO- $d_{6}$ and the NMR spectra were

(4) That is, to be used in advanced steps of the total synthesis of complex natural products. See: (a) Burés, J.; Isart, C.; Vilarrasa, J. Org Lett. 2007, 9, 4635-4638 and references therein. (b) Burés, J.; Vilarrasa, J. Tetrahedron Lett. 2008, 49, 441-444. (c) Burés, J.; Isart, C.; Vilarrasa, J. Org. Lett. 2009, 11, 4414-4417. 
Scheme 1. Formation of Enamines from 1

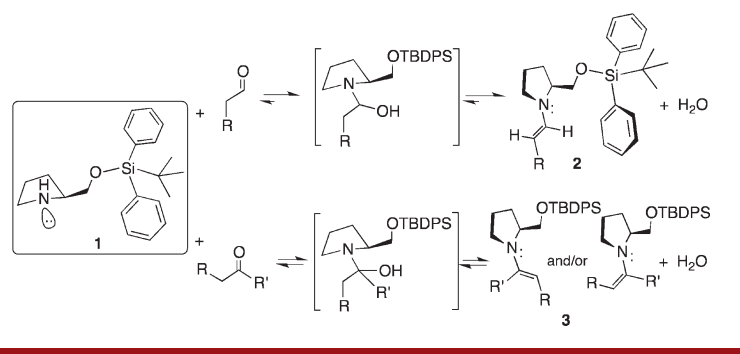

registered immediately, the signals corresponding to the expected enamines were clearly observed (2a-d, Figure 1$)$. NOESY experiments indicated that these were the main conformers (s-trans), in agreement with other aldehyde enamines. ${ }^{5}$ In all these cases, the equilibria were strongly shifted toward the formation of the respective enamines. As hemiaminal-type intermediates (drawn in Scheme 1) were not detected, we concluded that their dehydration is very fast, in a hygroscopic solvent such as DMSO; iminium hydroxydes were not detected either.

With ketones such as cyclohexanone and cyclopentanone, the equilibrium positions were not so readily attained - they took around $30 \mathrm{~min}$ - and they were not so shifted toward the corresponding enamines $\mathbf{3 e}$ and $\mathbf{3 f}$ (Figure 2). NOESY experiments indicated intense cross peaks of their olefin proton with the $\mathrm{CH}$ of the pyrrolidine ring and with the $\mathrm{NCH}_{2}$ protons on the other side, as well as less intense cross peaks with the $\mathrm{CH}_{2} \mathrm{O}$ protons; we believe that the two major conformations (with the rings almost coplanar) are in rapid equilibrium. At the probe temperature, the equilibrium constant for the formation of

(5) (a) Grošelj, U.; Seebach, D.; Badine, D. M.; Schweizer, W. B.; Beck, A. K.; Krossing, I.; Klose, P.; Hayashi, Y.; Uchimaru, T. Helv. Chim. Acta 2009, 1225-1259 (NMR and X-ray of the enamine from diphenylprolinol trimethylsilyl ether and 2-phenylethanal). (b) Schmid, M. B.; Zeitler, K.; Gschwind, R. M. Angew. Chem., Int. Ed. 2010, 49, 4997-5003 (detection by EXSY NMR of enamines from proline). (c) Bock, D. A.; Lehmann, C. W.; List, B. Proc. Natl. Acad. Sci. U.S.A. 2010, 107, 20636-20641 (crystal structures of proline enaminones). For related, additional examples, see: (d) Peelen, T. J.; Chi, Y.; Gellman, S. H. J. Am. Chem. Soc. 2005, 127, 11598-11599 (enamine from a MacMillan catalyst and 3-phenylpropanal). (e) Marquez, C.; Metzger, J. O Chem Commun 2006, 1539-1541 (ESI-MS of the enamine from proline and acetone). (f) Bertelsen, S.; Marigo, M.; Brandes, S.; Diner, P.; Jørgensen, K. A. J. Am. Chem. Soc. 2006, 128, 12973-12980 (dienamine from 2-pentenal). (g) Seebach, D.; Grošelj, U.; Badine, D. M.; Schweizer, W. B.; Beck, A. K. Helv. Chim. Acta 2008, 91, 1999-2034 (preceding communication of ref 5a). (k) Zhu, X: Tanaka, F; Lerner, R. A.; Barbas, C. F.; Wilson, I. A. J. Am. Chem. Soc. 2009, 131, 18206 (an enaminone intermediate). (i) Domínguez de María, P.; Bracco, P.; Castelhano, L. F.; Bargeman, G. ACS Catal. 2011, 1, 70-75 (NMR, enamine from $O$-methylprolinol and 2-methylpropanal). For enamines from prolinol ethers and propanal or 3-methylbutanal (appeared when the draft of this Ms was already written), see: (j) Schmid, M. B.; Zeitler, K.; Gschwind, R. M. Chem. Sci. 2011, 2, 1793-1803. (k) Schmid, M. B.; Zeitler, K.; Gschwind, R. M. J. Am. Chem. Soc. 2011, 133, 7065-7074. Also see: (1) Hein, J. E.; Burés, J.; Lam, Y.; Hughes, M.; Houk, K. N.; Armstrong, A.; Blackmond, D. G. Org. Lett. 2011, 13, 5644-5647 (enamine from proline and propanal). For pioneering papers, see refs 9 and 10 in ref 1d, as well as: (m) Blarer, S. J.; Seebach, D. Chem. Ber 1983, 116, 3086-3096 ( $\beta$-tetralone enamines). (n) Seebach, D.; Missbach, M.; Calderari, G.; Eberle, M. J. Am. Chem. Soc. 1990, 112, 7625-7638 (several enamines).

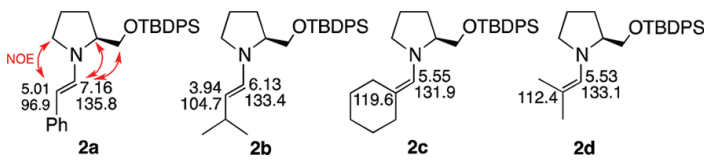

Figure 1. Representative aldehyde enamines, with relevant ${ }^{1} \mathrm{H}$ and ${ }^{13} \mathrm{C}$ chemical shifts in DMSO- $d_{6}$. For the olefin protons of 2a and $\mathbf{2 b},{ }^{3} J_{\mathrm{HH}}=13.9 \mathrm{~Hz}$

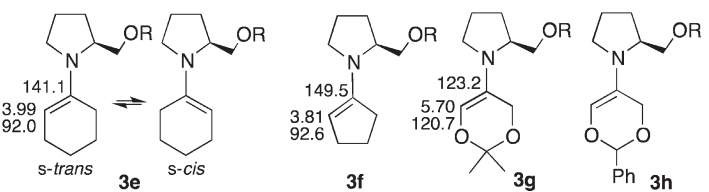

Figure 2. Representative ketone enamines, with relevant chemical shifts in DMSO- $d_{6}(\mathrm{R}=$ TBDPS).
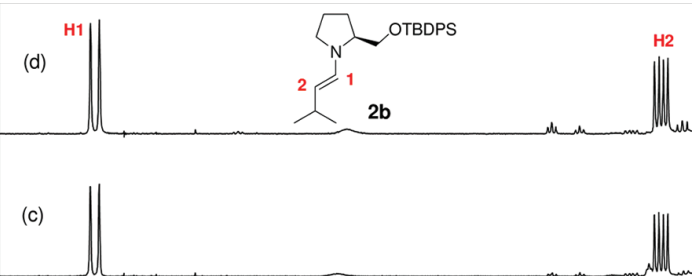

(b)

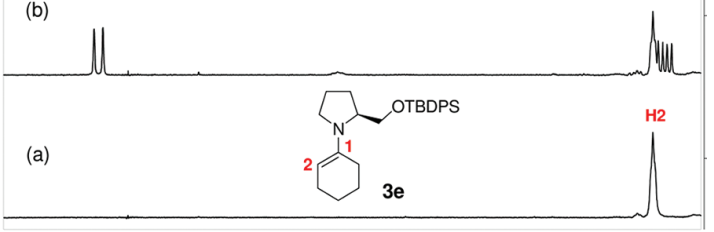

$\begin{array}{llllllllllllllllllllllllllllllllllll}5.5 & 6.4 & 6.3 & 6.2 & 6.1 & 6.0 & 5.9 & 5.8 & 5.7 & 5.6 & 5.5 & 5.4 & 5.3 & 5.2 & 5.1 & 5.0 & 4.9 & 4.8 & 4.7 & 4.6 & 4.5 & 4.4 & 4.3 & 4.2 & 4.1 & 4.0 & 3.9 & 3.4 .\end{array}$

Figure 3. ${ }^{1} \mathrm{H}$ NMR spectra (partial) in DMSO- $d_{6}$ of the reaction of enamine 3e with $\left(\mathrm{CH}_{3}\right)_{2} \mathrm{CHCH}_{2} \mathrm{CHO}$ (3-methylbutanal) to give enamine $\mathbf{2 b}$ and cyclohexanone: (a) spectrum of $\mathbf{3 e}$; (b) after addition of 0.3 equiv of 3 -methylbutanal; (c) + further 0.4 equiv of 3-methylbutanal; (d) + 0.4 equiv of 3-methylbutanal, again.

cyclohexanone enamine $\mathbf{3 e}$, determined from the proton areas in DMSO- $d_{6}$, was 0.78 (henceforward 0.8 ). This $K_{\text {eq }}$ value is 2 or 3 orders of magnitude lower than those of aldehyde enamines $\mathbf{2 a}-\mathbf{d}$. In fact, when we added 3methylbutanal to an NMR tube with a DMSO- $d_{6}$ solution of $\mathbf{3 e}$ (prepared from mixing $\mathbf{1}$ and cyclohexanone in the presence of activated $4-\AA \mathrm{A}$ MS), there was a quick exchange (completed by adding stoichiometric amounts of the aldehyde, see Figure 3) to give $\mathbf{2 b}$ and "free" cyclohexanone.

Cyclopentanone enamine $\mathbf{3 f}$ was formed in a higher percentage than $\mathbf{3 e}\left(K_{\mathrm{eq}}=2.33\right.$, hereafter 2.3). Dioxanone 
enamine $\mathbf{3 g}$ was much more stable than $\mathbf{3 f}\left(K_{\mathrm{eq}} \approx 75\right)$. In fact, as shown in Figure 4, addition of 1,3-dihydroxyacetone isopropylidene acetal (2,2-dimethyl-1,3-dioxan-5-one) to a 3e solution caused a full exchange reaction to give $\mathbf{3 g}$ and cyclohexanone (better followed by ${ }^{13} \mathrm{C} \mathrm{NMR}$, as there is an overlap of signals in ${ }^{1} \mathrm{H}$ NMR). 2-Phenyl-1,3-dioxan-5one gave a more stable enamine (3h) yet, in fact, a 1:1.2 mixture of two diastereomers $(\delta \mathrm{H} 5.54$ and $\delta \mathrm{C} 97.3$ for one $"=\mathrm{CH} ", \delta \mathrm{H} 5.48$ and $\delta \mathrm{C} 97.1$ for the second).

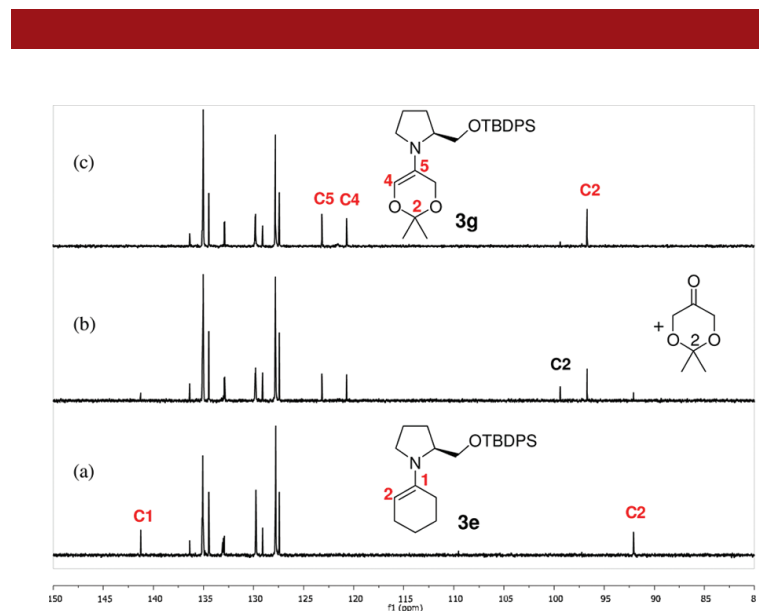

Figure 4. ${ }^{13} \mathrm{C}$ NMR spectra (partial) in DMSO- $d_{6}$ of the reaction of enamine 3e with 2,2-dimethyl-1,3-dioxan-5-one: (a) spectrum of 3e; (b) after addition of 2,2-dimethyl-1,3-dioxan-5-one (1 equiv), registered immediately; (c) $1 \mathrm{~h}$ later.

Since in $\mathrm{CDCl}_{3}$ the percentages of enamines in the equilibria were orders of magnitude lower (e.g., almost $10^{3}$ times lower for $\mathbf{2 b}$ and $\mathbf{3 g}$ ), we went on using DMSO- $d_{6}$ for subsequent comparisons.

The two most stable enamines we examined-see the first row of Figure 5-are those with the double bond conjugated with an aromatic ring; in these two cases there is no steric inhibition or hindrance to the electronic delocalization. ${ }^{1 \mathrm{a}, 5}$ In this regard, the case of the enamine of 1-phenylacetone, $\mathrm{PhCH}_{2} \mathrm{COCH}_{3}$ (fifth row), when it is compared to phenylethanal, $\mathrm{PhCH}_{2} \mathrm{CHO}$, is dramatic: the $\mathrm{CH}_{3}$ group causes a decrease from $K_{\text {eq }} \approx 3000$ to $K_{\text {eq }} \approx 0.6$. An additional $\mathrm{Ph}$ at the more substituted position of $\mathrm{PhCH}_{2} \mathrm{COCH}_{3}$ (see $\mathrm{Ph}_{2} \mathrm{CHCOCH}_{3}$, last row of Figure 5) is also contraindicated, as no enamine was detected.

As expected, aldehydes $\mathrm{RCH}_{2} \mathrm{CHO}$ gave enamines that are relatively more stable (for example, $\mathbf{2 b})^{7}$ than those of $\alpha$-branched aldehydes ( $\mathbf{2} \mathbf{c}$ and $\mathbf{2 d}$ ) and than those of most ketones. The exceptions to this rule are the astonishingly stable dioxanone enamines $\mathbf{3 g}$ and $\mathbf{3 h}$. During the treatment of an equimolar mixture of cyclohexanone and a dioxanone

(6) (a) Liu, F.; Wang, S.; Wang, N.; Peng, Y. Synlett 2007, 2415-2419. (b) Wang, C.; Yu, C.; Liu, C.; Peng, Y. Tetrahedron Lett. 2009, 50, 2363-2366.

(7) Butanal and pentanal showed a slightly higher tendency than 3-methylbutanal to give enamines with $\mathbf{1}$, but a higher percentage of aldol reaction products were soon formed (the NMR spectra were not so clean).

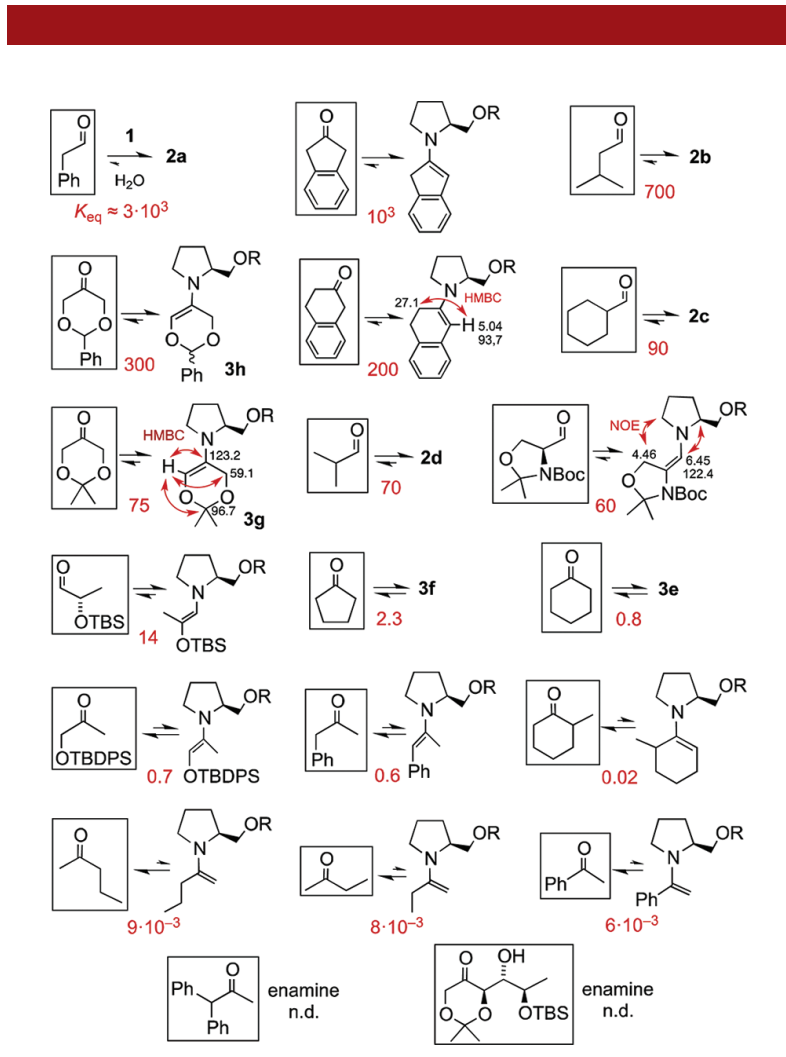

Figure 5. Equilibrium constants for the formation of enamines from 1 , as determined by ${ }^{1} \mathrm{H}$ NMR in DMSO- $d_{6}$ at $25^{\circ} \mathrm{C}$. $\mathrm{R}=$ TBDPS. The configurational isomers and major conformations depicted for each enamine are those indicated by NMR spectra. The values for several members of the series (especially, the first five and last four values) are approximate, although qualitatively correct, as they were obtained by addition of $\mathbf{1}$ to pairs of close carbonyl compounds mixed in different ratios. The enamines of the two last ketones could not be detected (n.d.), even with pyrrolidine instead of $\mathbf{1}$ and with large excesses of their ketones. In the case of phenylacetaldehyde (first substrate), a minor conformer (s-cis, $15 \%$ ) was noted just after mixing $\mathbf{1}$ and $\mathrm{PhCH}_{2} \mathrm{CHO}$ ( $\delta 5.55$ and $6.97,{ }^{3} J=15.6 \mathrm{~Hz}$ ), which decreased soon to $\leq 7 \%$.

(or of a complex molecule that contained both types of cyclic carbonyl groups) with a catalytic amount of a secondary amine such as $\mathbf{1}$, the percentage of $\mathbf{3 e}$ would be 100 times lower than that of $\mathbf{3 g}$ or 400 times lower than that of $\mathbf{3 h}$; unless the reactivity of $\mathbf{3} \mathbf{e}$ with a sort of electrophiles was really much higher than that of $\mathbf{3} \mathbf{g} / \mathbf{3} \mathbf{h}$, no products coming from $3 \mathbf{e}$ would be obtained. Furthermore, enamines $\mathbf{3 g}$ and $3 \mathbf{h}$ are formed in larger percentages than those of several $\alpha$-branched aldehydes; for example, the relative equilibrium constant for the formation of $\mathbf{3 g}\left(K_{\mathrm{eq}} \approx 75\right)$ is several times higher than that for $\alpha$-OTBS-propanal enamine $\left(K_{\mathrm{eq}} \approx 14\right){ }^{8}$

(8) It could explain why the cross-aldol reaction (enamine of $\mathbf{3} \mathbf{g}$ attacking the aldehyde group of $\alpha$-OTBS-propanal) predominates over self-aldol reactions when both carbonyl groups are treated with proline. For a review of organocatalytic aldol reactions of 1,3-dioxan-5-ones; see: (a) Enders, D. Narine, A. A. J. Org. Chem. 2008, 73, 7857-7870. For a computational study, see: (b) Calderón, F.; Doyagüez, E. G.; Cheong, P. H.-Y.; FernándezMayoralas, A.; Houk, K. N. J. Org. Chem. 2008, 73, 7916-7920. For pioneering work on dioxanones, see: (c) Majewski, M.; Gleave, D. M. Nowak, P. Can. J. Chem. 1995, 73, 1616-1626. 
With acyclic ketones, it was more difficult to detect the corresponding enamines. Therefore, we mixed $\mathbf{1}$ with 10-20 equiv of ketone (we admit that the solvent polarity changes, but we had no other choice). As we could not determine with accuracy the corresponding equilibrium constants, in order to better compare the tendency of diverse carbonyl groups to give enamines, we prepared series of NMR tubes; they contained pairs of carbonyl compounds in equimolar amounts and later in different amounts (with a large excess of the carbonyl compound the enamine of which was formed in lower percentage), to which 1 was added. The relative $K_{\text {eq }}$ values that we obtained from integration of the areas of the olefin protons, taking enamine $3 \mathbf{f}$ as the reference, are also shown in Figure 5.

The last ketones of Figure 5 (2-pentanone, 2-butanone, etc.), the enamines of which with 1 could hardly be observed, were compared to the preceding partners by using pyrrolidine ${ }^{9}$ (see Supporting Information). This afforded values of $K_{\text {eq }}$ larger than with $\mathbf{1}$, although the relative order was maintained). The values given in Figure 5 take into account the corresponding correction. Thus, the $K_{\text {eq }}$ values of the penultimate row of Figure 5 are approximate (but an approximate scale is better than nothing).

By comparing cyclohexanone $\left(K_{\mathrm{eq}}=0.8\right)$ with 2methylcyclohexanone $\left(K_{\text {eq }}=0.02\right)$, the sensitivity of the relative enamine stabilities to the steric effects ${ }^{1 \mathrm{a}}$ is corroborated again. Despite the fact that cyclic ketones are much better substrates for aldol-like reactions than analogous acyclic ketones, a simple $\alpha$-Me substituent shifts the equilibria with both regioisomeric enamines toward the left. If the side chain is bulkier (for example, if the substrate is an aldol product, such as the dioxanone at the ultimate row of Figure 5), no enamine could be detected; this occurred even by mixing $\mathrm{PhCOCH}_{3}$ and such an aldol in a 1:20 ratio and using an excess of pyrrolidine. Its relative $K_{\text {eq }}$ is below our detection limit.

We have carried out calculations (see the Supporting Information) at a DFT level in DMSO for the geometry optimizations, followed by single-point calculations of the total energies at MP2 level in DMSO, to compare the conformers of several enamines of Figure 5. The results agree qualitatively with those obtained by NMR.

In summary, by standard NMR experiments we have confirmed or rediscovered rules for enamines that do not differ from those known or assumed for a long time, ${ }^{1,10}$ but

(9) With pyrrolidine, more aldol-like products were formed, but the spectra could be better analyzed since the signals of the side chain $\left(\mathrm{CH}_{2} \mathrm{OSi}\right)$ of $\mathbf{1}$ and its enamines were avoided.

(10) (a) Enamines of $\mathrm{RCH}_{2} \mathrm{CHO}$, especially if these enamines are conjugated $(\mathrm{R}=\mathrm{Ar}, \mathrm{EWG})$, are the most stable (as known or expected). (b) A methyl or linear alkyl group on the other side of the carbonyl group (e.g., any $\mathrm{RCH}_{2} \mathrm{COCH}_{3}$ ) is very detrimental for the formation of any possible enamine, unless the conjugation of the enamine system with an aromatic ring or EWG is feasible (i.e., not inhibited by steric effects), as known. (c) Enamines of cyclic ketones (entropic component of the steric effect) are relatively more stable than those of the analogous or similar acyclic ketones. (d) Branching at $\alpha$ or $\alpha^{\prime}$ positions of a CO group is deleterious, as equilibrium constants may be reduced by a factor of $10-100$ for an aldehyde and by $10^{3}-10^{5}$ for a ketone, being branching at both $\alpha$ and $\alpha^{\prime}$ positions, obviously, more deleterious yet. These details are key in practice: if enamines are not formed at all or are hardly formed, no "enamine-catalyzed" or enamine-involving reactions will occur. henceforward the comparisons of aldehydes and ketones can be established on a quantitative basis. ${ }^{10 \mathrm{~d}}$ For example, when, via a secondary amine-catalyzed reaction, a linear aldehyde reacts with an electrophile, the product, which becomes an $\alpha$-branched-like aldehyde, shows a $10-100$ times weaker tendency to form its enamine (fortunately, otherwise the newly created stereocenter would soon racemize and, with strong electrophiles, double substitution could occur); ${ }^{11}$ if a ketone $\mathrm{RCH}_{2} \mathrm{COCH}_{2} \mathrm{R}^{\prime}$ reacts via one of its enamines with an electrophilic carbon atom, the product, let us say $\mathrm{RCH}_{2} \mathrm{COCHR}^{\prime} \mathrm{R}^{\prime \prime}$, will show a tendency $>1000$ times weaker to form an enamine.

In short, the trend to afford enamines with 1 (and pyrrolidine) can be summarized as follows:

\section{$\mathrm{ArCH}_{2} \mathrm{CHO} \gg$}

benzo[c]cycloalkanones $\approx$ linear aldehydes $\gg$

3,5-dioxacyclohexanones $\approx \alpha$-branched aldehydes $\gg$ cycloalkanones $\left(K_{\mathrm{eq}} \approx 2.3-0.8, \mathrm{DMSO}\right) \approx$ $\mathrm{YCH}_{2} \mathrm{COCH}_{3}(\mathrm{Y}=\mathrm{OR}, \mathrm{Ph}) \gg$

2-Me-cyclohexanone $>$ linear ketones $\approx \mathrm{PhCOCH}_{3}$ $\alpha$-branched ketones

Thus, there are two groups of ketones with a higher tendency than several aliphatic aldehydes to afford enamines: (a) those cyclic ketones that can give fully conjugate enamines (e.g., benzo[c]cycloalkanones), as expected; ${ }^{1,5}$ (b) cyclic 1,3-dihydroxyacetone derivatives, such as the known 2,2-dimethyl-1,3-dioxan-5-one ${ }^{8}$ and the amazing 2-phenyl-1,3-dioxan-5-one, enamines of which (see $\mathbf{3 g}$ and 3h), to the best of our knowledge, have been spectroscopically characterized and reported here for the first time.

Acknowledgment. This study was started with funds from Grant No. CTQ-2006-15393 (Spanish Government) and continued with Grant No. CTQ2009-13590 (20102012) and with a gift from the AGAUR (2009SGR825). D.S. holds a studentship of the University of Barcelona (UB), C.I. had a similar studentship (2007-2010), and J.B. was an instructor (Ajudant LOU, 2008-2009) and then a postdoctoral fellow of Fundació Cellex de Barcelona (Sep 2009-June 2010). Thanks are also due to the graduate student L. Pérez for preliminary calculations in the fall of 2009 and to the Master student H. Carneros for a sample of 2-phenyl-1,3dioxan-5-one.

Supporting Information Available. Experimental details and copies of ${ }^{1} \mathrm{H}$ and ${ }^{13} \mathrm{C}$ NMR spectra and 2D NMR experiments, as well as results of calculations at the MP2//DFT level. This material is available free of charge via the Internet at http://pubs.acs.org.

(11) Acetaldehyde (ethanal) is a particular case. After the first substitution by reaction with an electrophile $\left(\mathrm{R}^{\delta+}\right.$ or $\left.\mathrm{E}^{\delta+}\right)$, the intermediate enamine $\left(\mathrm{R}-\mathrm{CH}=\mathrm{CH}-\mathrm{NR}^{\prime}{ }_{2}\right.$ or $\left.\mathrm{E}-\mathrm{CH}=\mathrm{CH}-\mathrm{NR}^{\prime}{ }_{2}\right)$, of a $\mathrm{RCH}_{2} \mathrm{CHO}$-type aldehyde, is still very amenable to a second substitution. For examples, see: (a) Chandler, C.; Galzerano, P.; Michrowska, A.; List, B. Angew. Chem., Int . Ed. 2009, 48, 1978-1980. (b) Coeffard, V.; Desmarchelier, A.; Morel, B.; Moreau, X.; Greck, C. Org. Lett. 2011, 13, 5778-5781 and ref 4 cited therein. 